\title{
Quando o preconceito marca mais que a doença. ${ }^{1}$
}

\section{When the prejudice marks more than the disease.}

\section{Cuando el prejuizio marca mas de lo que la enfermedad.}

\author{
Iací Proença PALMEIRA ${ }^{1}$ \\ Ana Beatriz de Azevedo QUEIROZ ${ }^{2}$ \\ Márcia de Assunção FERREIRA ${ }^{3}$
}

\begin{abstract}
RESUMO: Objetivou-se identificar e analisar as representações sociais do contágio da hanseníase por mulheres com o corpo alterado por esta doença, e suas conseqüências para a vida sócio-familiar. Pesquisa qualitativa e descritiva, com aplicação da teoria das representações sociais. Participaram quarenta e três mulheres atendidas em uma Unidade de Referência Especializada em dermatologia sanitária. Realizou-se entrevista individual e observação sistemática. Realizou-se análise lexical, através do software ALCESTE. Os resultados evidenciam representações sobre o contágio da hanseníase remetendo à lepra, ao preconceito e ao confinamento nas colônias, inclusive com separação de utensílios domésticos. Conclui-se sobre a importância da desconstrução destas representações, considerandoasubjetividadepeloacessoàhistóriados sujeitosoqualpossibilitaentenderos significados que estes atribuem ao adoecimento e suas implicações relacionadas ao estigma da hanseníase.
\end{abstract}

Palavras-chave: Hanseníase. Preconceito. Saude da mulher. Enfermagem.

ABSTRACT: It aimed at identifying and analyzing the leprosy's contagion social representations by women with the body altered by this disease, and its consequences for the social-familiar life. Qualitative and descriptive research, with application of the social representations theory. Participated forty-three women attended in a Specialized Reference Unit in sanitary dermatology. It realized individual interview and systematic interview. It realized lexical analysis, through the ALCESTE software. The results evidence representations about the leprosy contagion sending 1Graduada em Enfermagem pela Universidade do Estado do Pará (1981), mestre em Educação pelo Instituto Latino-Americano e Caribeño (IPLAC-Cuba)/Universidade do Estado do Pará (2000) e doutora em Enfermagem pela Universidade Federal do Rio de Janeiro/Escola de Enfermagem Anna Nery (2011). Contato: iaci_palmeira@yahoo. com.br 2 ??????

3 Graduada em Enfermagem pela Universidade Federal do Rio de Janeiro (1987), mestre em Educação pela Universidade do Estado do Rio de Janeiro (1995) e doutora em Enfermagem pela Universidade Federal do Rio de Janeiro (1999). 
to the leprosy, to the preconception in the colonies, including with separation of household utensils. It concluded about the deconstruction of these representations, considering the subjectivity by the access to the subjects' $\mathrm{s}$ history which makes possible understanding the meanings that these attribute to the illness and its implications related to the leprosy' s stigma.

Keyword: Leprosy. Prejudice. Women's Health. Nursing.

RESUMEN: Se objetivo identificar y analizar las representaciones sociales del contagio de la lepra por mujeres con el cuerpo alterado por esta enfermedad, y sus consecuencias para la vida social y familiar. Investigación cualitativa y descriptiva, con aplicación de la teoría de las representaciones sociales. Participaron cuarenta y tres mujeres atendidas en una Unidad de Referencia Especializada en dermatología sanitaria. Se realizo entrevista individual y observación sistemática. Se realizó análisis léxica, a través del Programa ALCESTE. Los resultados evidencian representaciones sobre el contagio que remeten a concepciones anticuas sobre la lepra, al prejuicio y al confinamiento en las colonias, inclusive con separación de utensilios domésticos. Se concluye sobre la importancia de la deconstrucción de estas representaciones, considerando la subjetividad por el acceso a la historia de los sujetos, lo cual posibilita entender los significados que estos atribuyen al proceso de se enfermar y sus implicaciones relacionadas al estigma de la lepra.

Palabras claves: Lepra. Prejuicio. Salude de la mujer. Enfermería.

\section{INTRODUÇÃO}

A hanseníase é doença milenar que forma um vasto campo de representações sociais no imaginário social, devido ao seu passado carregado de sofrimentos, dores, mutilações e isolamento social. A menção de seu nome associada à possibilidade de estar acometida pela hanseníase, ainda hoje atemoriza e aterroriza as pessoas.

A produção da imagem de terror deve-se aos antigos leprosários e suas inumeráveis histórias de sofrimento, exclusão e morte social, como, também, de seus habitantes, cujos corpos são descritos com lesões ulceradas disseminadas, deformidades ${ }^{1}$, perdas de partes do corpo, um pano na cabeça no afã de esconder o rosto desfigurado pela doença. É a circulação dessa imagética que atravessou os séculos e ainda hoje, em pleno século XXI, dá forma e nome à hanseníase e seus doentes.

As políticas oficiais de saúde baseadas no confinamento dos portadores de hanseníase em instituições asilares, separando-os de seus familiares e da sociedade em geral, eram, na época, a única forma de prevenção da doença, e muito contribuíram para o estigma da lepra. Em 1930, o isolamento compulsório foi adotado em todo o Brasil e o combate à lepra se tornou sistemático em hospitais colônia, visando muito mais à separação do enfermo que a um tratamento que pudesse curá-lo. ${ }^{1}$ Essa política sanitária, prevencionista e isolacionista, baseava-se no modelo tripé, ou seja, compunha-se do leprosário, que era o local em que deveriam ser internados os leprosos; 
o dispensário era o local destinado a abrigar as pessoas que tiveram contato com o doente; e o preventório, local destinado aos filhos dos doentes, sendo estes compulsoriamente afastados de seus pais.

Até os anos sessenta, o isolamento era uma política incontestável de combate à lepra, sendo o medo do contágio da doença tão grande, que abrangia objetos e tudo o mais que fosse tocado pelo doente. $^{1-2}$ De modo a impossibilitar qualquer tipo de contato com as pessoas que não tinham a doença, as colônias de leprosos possuíam moeda própria, na qual em uma de suas faces continha o Hospício de Lázaro. ${ }^{3}$ Somente a partir de 1980 é que houve uma reviravolta na política de combate à lepra, com a desativação das colônias de hansenianos e uma grande campanha de reintegração dos doentes às suas famílias, bem como o tratamento ambulatorial da hanseníase. ${ }^{2}$

Assim, compreender que impacto o imaginário da Lepra teve sobre as práticas sociais e como produziu suas representações na hanseníase permite localizar a herança que nos foi legada por àquela, tendo em vista os grupos sociais compartilharem um imaginário comum ou central sobre a doença.

Nessa perspectiva, ser portador de hanseníase configura-se numa vivência desencadeante de grande vulnerabilidade psicológica não só por se tratar de uma doença potencialmente incapacitante, mas, também, porque sua trajetória terapêutica induz, muitas vezes, a alterações estigmatizantes na imagem corporal (reações hansênicas) que repercutem na autoestima e na identidade desses portadores.

Assim, as representações sociais do contágio da hanseníase é o objeto de estudo tratado neste artigo, cujos objetivos são: 1) Identificar e analisar as representações sociais do contágio da hanseníase sob a ótica de mulheres com o corpo alterado pela hanseníase; 2) Discutir as consequências de tais representações para as vidas sócio-familiares das mulheres.

Ao se refletir sobre a subjetividade das mulheres sobre o contágio e o que ela produz ao reelaborar seu conhecimento, busca-se o reconhecimento de suas representações que engloba comportamentos significantes, sentimentos e expressões corporais.

Para tanto, levou-se em conta que a vida social comunitária é dotada de aspectos simbólicos particulares, que compõem a cultura onde subsistem representações sociais, tradições, regras e modos de vida concebidos nas relações interpessoais ao longo do tempo. A partir de então, brotam símbolos e representações que influenciam o comportamento pessoal de seus membros e os levam a criar novos conhecimentos e representações a partir dos conhecimentos pré-existentes. ${ }^{4}$

\section{METODOLOGIA}

Trata-se de um estudo descritivo com abordagem metodológica qualitativa, baseado na Teoria das Representações Sociais, vertente psicossocial de Serge Moscovici. As representações sociais 
se constituem como uma série de opiniões, explicações e afirmações que são produzidas a partir do cotidiano dos grupos. São consideradas como teorias do senso comum, criadas pelos grupos para explicar a realidade. ${ }^{5}$

O cenário de estudo foi uma Unidade de Referência Especializada (URE) em Dermatologia Sanitária localizada no município de Marituba-Pará, palco de uma ex-colônia de hansenianos. Os sujeitos estudados foram 43 mulheres com alterações corporais pela hanseníase. Para justificar a opção pela mulher como sujeito do estudo, buscou-se apoio em uma pesquisa sobre os efeitos da hanseníase em homens e mulheres ${ }^{6}$, cuja conclusão foi que os homens reagem de modo diferente das mulheres quanto aos efeitos biológicos e psicológicos provocados pela hanseníase. Por outro lado, o corpo-mulher requer cuidados diferentes do corpo-homem, não só quanto ao tipo de cuidado como à forma de sua realização. ${ }^{7}$ Além do que, uma pesquisa sobre as representações sociais do homem paciente de hanseníase ${ }^{2}$ constatou que eles não previnem as doenças como as mulheres o fazem; o cuidado com o corpo tem relação com o comportamento de gênero e a preocupação com o trabalho é muito acentuada nos homens, pois estes, segundo a autora, são os provedores majoritários da família.

Dessa forma, os resultados expressos revelam que as representações sociais da hanseníase, bem como seus efeitos no corpo e os cuidados com esse corpo alterado, têm uma construção diferente daquelas dos homens. $\mathrm{O}$ exposto relaciona-se com os fatores de natureza individual, histórica, psicossocial, cultural, entre outros, que estruturam o universo feminino, caracterizando-se numa mundividência que repercute diretamente na formação das suas representações sociais. ${ }^{8}$

Os critérios de inclusão para a pesquisa foram: 1) estar na idade adulta legal, ou seja, faixa etária de 18 a 59 anos; 2) residir no município de Marituba-Pa ou Ananindeua-Pa; 3) estar matriculada na instituição eleita para local de estudo; 4) estar fazendo qualquer tipo de tratamento na URE mesmo que esteja de alta curada, tais como: tratamento para estado reacional e/ou estar em tratamento fisioterápico e/ou com terapeuta ocupacional para prevenção de incapacidades físicas e/ou estarem fazendo curativo, entre outros; 5) aceitar participar do estudo. Por outro lado, foram considerados critérios de exclusão: 1) as mulheres que tivessem qualquer alteração corporal que não fosse causada pela hanseníase; 2) estar gestante e/ou puérpera e 3) ser ex-moradora da Colônia de Marituba.

A coleta dos dados realizou-se no período de julho a dezembro de 2009, a partir da técnica de entrevista individual guiada por um roteiro semi-estruturado e da observação sistemática em sala de espera. Os registros verbais foram feitos por gravação magnética e as expressões não verbais foram registradas em um caderno de campo.

Os dados oriundos da entrevista foram submetidos ao software ALCESTE (Analyse Lexicale par Contexte d'un Ensemble de Segments de Texte), o qual organiza e sintetiza as informações importantes usando como base metodológica a abordagem conceitual dos mundos lexicais. ${ }^{9}$ Os 
dados são organizados através de análises estatísticas e matemáticas, fornecendo o número de classes, as afinidades entre estas, as divisões feitas no corpus analisado até a constituição das classes, as formas radicais e palavras associadas com seus valores de $\mathrm{X}^{2}$, afora o contexto semântico de cada classe. ${ }^{10}$

O ALCESTE segmenta o corpus em unidades cognominadas de unidades de contextos iniciais (UCI). Posteriormente, o corpus é reformatado e decomposto em segmentos de algumas linhas, os quais são designados de unidades de contextos elementares (UCE) e equivalem ao material discursivo ou escrito relevante à formação das classes. ${ }^{10}$

No que se refere aos aspectos éticos da pesquisa, respeitaram-se os princípios da Resolução no 196/96 do Ministério da Saúde. O projeto foi aprovado pelo Comitê de Ética em Pesquisas da Escola de Enfermagem Anna Nery e Hospital Escola São Francisco de Assis, da Universidade Federal do Rio de Janeiro sob o Protocolo no 31/2009. Dessa forma, cada participante formalizou o seu aceite assinando o Termo de Consentimento Livre e Esclarecido.

\section{APRESENTAÇÃO E ANÁLISE DOS RESULTADOS}

Este item constitui-se da apresentação e análise dos dados gerada pelo Programa ALCESTE, cujo corpus compõe-se de quarenta e três (43) unidades de contexto inicial (u.c.i). A partir de então, o software repartiu o corpus em 858 unidades de contexto elementar (u.c.e), formadas por 3453 palavras ou formas de vocábulos distintos. Posteriormente o programa reduziu os vocábulos às suas raízes, originando 619 palavras analisáveis e 225 palavras suplementares. De um total de 858 u.c.e, o programa selecionou 710 delas, o que perfaz $83 \%$ do corpus.

A análise lexical das 43 entrevistas distribuiu os conteúdos em quatro classes, cujas Classes 1 e 2 centraram-se nos sentidos do cuidado; e as Classes 3 e 4 centraram-se nos sentidos do preconceito.

Por meio da observação do dendrograma (figura 1) pode-se identificar que o Software dividiu o material discursivo em dois grandes grupos. Posteriormente, o primeiro grupo se dividiu e formou as classes 3 e 4 . Por sua vez, o segundo grupo também sofreu divisão originando as classes 1 e 2 . Dessa forma, as classes 3 e 4 possuem significados comuns que as diferenciam das classes 1 e 2 . Concomitante a isso, apesar de haver uma aproximação entre os significados das duas classes, elas possuem sentidos e ideias distintas entre si que servem para justificar a divisão feita pelo Programa, uma vez que se dividiram em etapas subsequentes da classificação hierárquica. Processo similar ocorreu com as classes 1 e 2 . 
Figura 1: Divisão das classes - Classificação Hierárquica Descendente

\author{
Classe $1-21,0 \%$
}

\author{
Classe $2-14,0 \%$
}

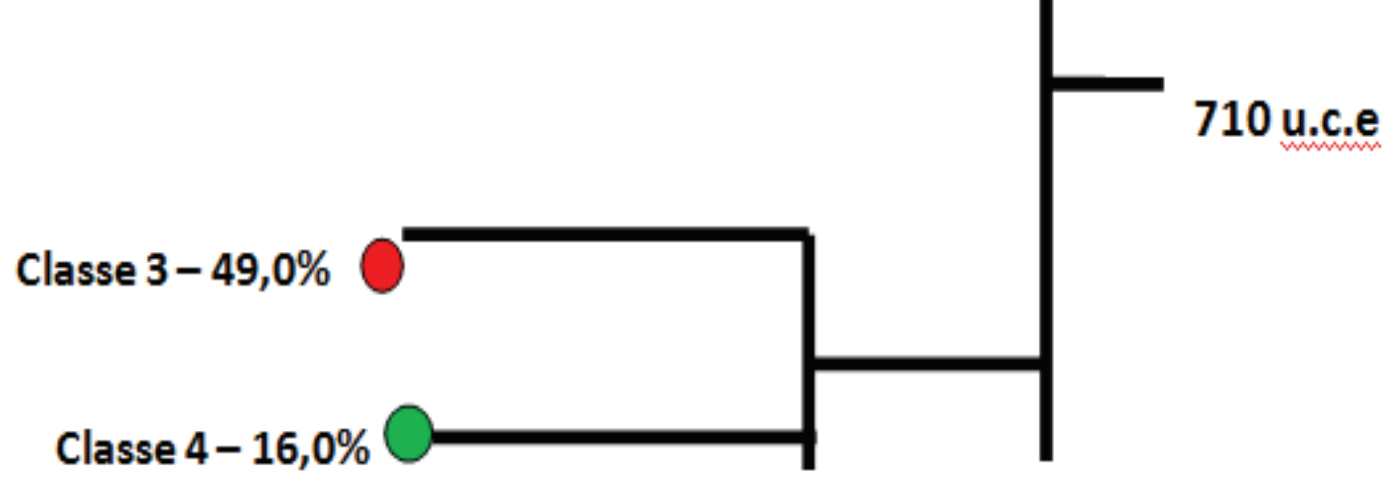

Fonte: Relatório resumido de resultados do Alceste

Cabe esclarecer que para fins desse artigo serão explorados e discutidos os conteúdos presentes na classe 4, denominada "Marcas causadas pelos outros: vivenciando o medo do contágio", uma vez que é nesta que se concentram os léxicos que exploram o objeto recortado para a discussão em tela.

Os resultados oriundos do Software (Quadro 1) informam as palavras com maior associação estatística à classe, ou seja maior $\mathrm{X}^{2}$, assim como as u.c.e. que tiveram maior impacto para a formação das mesmas.

As palavras com maior associação estatística à classe, ou seja, maiores valores do coeficiente de associação por meio do Qui-Quadrado $\left(X^{2} \geq 16\right)$, foram: mãe $\left(X^{2}=88\right)$, irmãos $\left(X^{2}=77\right)$, copo $\left(X^{2}=70\right)$, filha $\left(X^{2}=65\right)$, pai $\left(X^{2}=61\right)$, família $\left(X^{2}=60\right)$, mora $\left(X^{2}=59\right)$, filhos $\left(X^{2}=42\right)$, casa $\left(X^{2}=41\right)$, separar $\left(X^{2}=39\right)$, criança $\left(X^{2}=38\right)$, colher $\left(X^{2}=37\right)$, marido $\left(X^{2}=33\right)$, resultado $\left(X^{2}=33\right)$, beber $\left(X^{2}=30\right)$, mágoa $\left(X^{2}=27\right)$, prato $\left(X^{2}=26\right)$, amigos $\left(X^{2}=26\right)$, assunto $\left(X^{2}=26\right)$, papai $\left(X^{2}=22\right)$, chamar $\left(X^{2}=21\right)$, afastaram $\left(X^{2}=17\right)$, senti $\left(X^{2}=17\right)$, frente $\left(X^{2}=17\right)$, tia $\left(X^{2}=16\right)$, pena $\left(X^{2}=16\right)$.

Os vocábulos que possuem maiores valores do coeficiente de associação por meio do QuiQuadrado $\left(\mathrm{X}^{2}\right)$, foram: mãe, irmãos, copo, filha, pai, família, casa, separar, criança, colher, marido, os quais permitem depreender que os conteúdos se congregam em torno do contágio, mais especificamente do preconceito sofrido pelos familiares por medo do contágio. O preconceito 
é expresso pelos verbos separar e afastar, pela alusão aos utensílios de cozinha (copo, prato, colher) e pelo substantivo pena. No que tange aos léxicos: mãe, irmãos, filhos, pai, família, marido denotam que tal preconceito se situa no seio da família nuclear (marido, filhos), de entes mais próximos (pais e irmãos), de familiares mais distantes e de amigos (tia e amigos). Esse conteúdo representacional pode ser observado nas u.c.e. a seguir:

Eu digo que a dor maior não é ser discriminada pelas pessoas de fora, e sim pela própria família. Eu fui discriminada por uma tia minha, a filha dela teve um neném e quando eu ia pegar no neném ela vinha na frente e me tirava o neném. (u.c.e no 691 / u.c.i $\left.n^{\circ} 33\right)$.

[...] Eu já passei por muita discriminação, inclusive dentro de minha própria família. Eu sofri preconceito e continuo sofrendo desde criança, até a minha irmã me discriminou [...] (u.c.e $n^{o} 335$ / u.c.i $\left.n^{o} 15\right)$.

Conforme as u.c.e supracitadas, ainda hoje, o doente de ontem toma vulto em determinadas realidades, que parecem não ter tido poder suficiente para desconstruir a intensidade do preconceito entranhado em seus meios sociais. Percebe-se claramente o pensamento circulante socialmente acerca da hanseníase nas seguintes u.c.e.:

Eu nunca mais fui a casa dela. Eu me senti muito mal quando uma pessoa me falou que eu era leprosa, que eu tinha lepra e, por isso, eu estava doente e iria ficar ainda pior, toda podre. (u.c.e $n^{o} 137$ / u.c.i $n^{o}$ 6).

Dizem que pega, por isso eu disse logo para a minha filha que estava doente, que era lepra. Era assim que chamavam antes, lepra. [...]. (u.c.e $n^{o} 551$ / u.c.i $\left.n^{\circ} 25\right)$.

As u.c.e supracitadas remetem ao impacto social e psicológico que sofrem as mulheres ao serem chamadas de leprosas, pois esta alcunha, resistente aos avanços da ciência, causa mal-estar por evocar pessoas mutiladas, feias, caindo os pedaços do corpo e isoladas da sociedade, gerando graves alterações na autoimagem e autoestima de tais mulheres, que passam se ver desfiguradas, repulsivas e com dificuldades de relacionamentos.

No Brasil o termo lepra foi abolido e substituído pela palavra Hanseníase. Na década de 70, Abrão Rotberg propôs a mudança da terminologia de lepra para hanseníase com vistas a diminuir o estigma. ${ }^{11}$ Em 29 de março de 1995, torna-se obrigatório usar o termo hanseníase ao invés do termo lepra. ${ }^{12}$ Porém, neste estudo constatou-se que ainda hoje a lepra continua sendo usada para denominar ou servir de parâmetro para a hanseníase.

A hanseníase é uma doença cuja principal via de eliminação dos bacilos é a aérea superior, sendo o trato respiratório a mais provável via de entrada do Mycobacterium leprae no corpo. Assim, a transmissão se dá pela eliminação do bacilo através das gotículas oronasais de um portador 
multibacilar (Virchowianos e Dimorfos) que não tenha iniciado o tratamento específico, para as vias aéreas superiores de uma pessoa suscetível. ${ }^{13}$

No entanto, as pessoas têm um imaginário sobre o contágio que acaba influenciando e atravessando a representação social da hanseníase, por mais que se tenha o discurso técnicocientífico da desconstrução disso. Mesmo que as mulheres acometidas pela doença sejam orientadas com relação ao contágio e à multidrogaterapia e seu efeito deletério ao bacilo, tornando-o incapaz de infectar outras pessoas na primeira dose. Ainda assim, as crenças sobre o contágio perduram no imaginário, sendo evidenciado por frases que nutrem as crendices e mitos e geram comportamentos significantes, tais como: separar louças e talheres; não beijar; não tocar; afastar as crianças, dentre outros. Estes comportamentos aludem tratar-se de uma representação do contágio pelos líquidos corporais. Estes resultados são similares aos encontrados em um estudo sobre o contágio da Aids. ${ }^{14}$

A maior preocupação dessas mulheres é o fato de se tornarem objetos de preconceito e discriminação em qualquer lugar que estejam. Dessa forma, não haveria um refúgio melhor para fugir do estigma, do que a vida privada no lar entre os familiares. Porém, é no lar, em que supostamente encontrariam apoio e compreensão dos familiares para a superação dos problemas decorrentes da doença, onde começa o preconceito.

Tem pessoas que são preconceituosas, quando a minha família descobriu que eu estava doente todo mundo se afastou de mim. A minha mãe foi a primeira a se afastar por medo, ela mora em um município próximo, mas não me visita. Uma vez eu fui a casa dela e contei que estava doente, ela separou copo, prato e talher. (u.c.e $n^{\circ} 660$ / u.c.i $\left.n^{\circ} 31\right)$.

Só meu marido, meu pai, minha mãe e minhas irmãs sabem. Uma irmã ficou meio assim e eu briguei com ela, porque ela não queria beber no mesmo copo, comer com a mesma colher. (u.c.e $n^{\circ} 178$ / u.c.i $n^{\circ} 8$ ).

A característica central da situação cotidiana da vida dessas mulheres consiste nos problemas sociais, ou seja, aqueles causados pelo preconceito, pela não-aceitação da própria família e pelas situações constrangedoras em que são expostas, corroborando com outro estudo sobre o mesmo tema. ${ }^{15}$

O conhecimento comum produzido pela comunidade proporciona aos seus membros os parâmetros por meio dos quais as pessoas dão sentido ao mundo e relacionam suas próprias histórias a narrativas mais amplas da vida comunitária, as quais se enredam de tal maneira que quando a história de vida de uma pessoa é contada, ela reflete a história, os acontecimentos, as formas culturais e o comportamento de toda a comunidade. ${ }^{4}$

Diante do exposto, os comportamentos preconceituosos dos familiares das mulheres dessa pesquisa com relação à hanseníase refletem o conhecimento popular arcaico e as crendices // Tempus, actas de saúde colet, Brasília, 8(3), 53-66 set, 2014. 
arraigadas no que concerne ao contágio da doença, relacionando-o com o isolamento dos doentes e de tudo que fosse por eles tocado, numa alusão à política vigente nos tempos em que a Colônia de Marituba ainda servia para abrigar e segregar os hansenianos. Esta analise é importante para se saber que o entendimento do preconceito sofrido por tais mulheres requer o conhecimento do comportamento de quem estigmatiza, sendo este muito mais abrangente por relacionar-se ao comportamento do grupo de pertença.

A mulher com o corpo alterado pela hanseníase está sempre insegura em relação ao que pensam dela, como a receberão e como a identificarão. Decorrente disso, ela passa a ter comportamentos significantes por medo da rejeição e, assim, passa a não frequentar certos grupos sociais os quais frequentava anteriormente, deixa de vestir certas roupas e pode passar a evitar o contato afetivosexual em virtude do medo da rejeição do outro. Essa incerteza diante dos outros é ocasionada pelo fato que, intimamente ou não, os outros podem defini-la em termos de seu estigma.

[...] Eu não gosto mais de fazer, só faço por fazer. Quase sempre dói, dói as minhas pernas, enfim, dói tudo. Talvez eu não queira mais por revolta, por ele não me beijar mais, me chamar de leprosa e arrumar mulher na rua. Nenhuma mulher gosta disso. (u.c.e $n^{o} 76 /$ u.c.i $\left.n^{o} 3\right)$

[...] Não quero mais. Tenho nojo de me deitar com ele. O pior é que toda vez ele vem com a mesmo história e eu caio. Depois eu me arrependo e choro de raiva. É só para eu pegar filho, já são sete com esse menor que tem três meses [...]. (u.c.e $n^{\circ} 143$ / u.c.i $\left.n^{o} 6\right)$.

A sexualidade passou a ter um papel secundário na vida dessas mulheres, seja porque a intimidade entre os casais desnuda e expõe o corpo ao olhar do outro; ou pode advir de uma reação negativa como resposta ao preconceito expresso pelo parceiro, ou pela exacerbação de sintomas provocados pelas reações hansênicas.

Estes resultados corroboram os de outro estudo sobre sexualidade e hanseníase ${ }^{6}$, ao constatarem que a hanseníase não é um óbice para o ato sexual, porém pode servir de barreira para algumas manifestações de afeto tais como o beijo; e que mesmo as mulheres não sentindo prazer no ato sexual, elas figuram como objeto de satisfação dos homens, servindo-os, fazendo do ato sexual uma obrigação pelo fato de serem mulheres.

Pode-se então inferir que a diminuição do preconceito da hanseníase após a desativação dos leprosários, da mudança do termo lepra pela hanseníase, e da cura alcançada a partir do tratamento, não foi suficiente para minorar as atitudes preconceituosas de mudança de postura da sociedade ante as mulheres que têm o corpo alterado por essa doença, sejam portadoras ou ex-portadoras, uma vez que tais condutas estigmatizantes demonstram o desconhecimento sobre o modo de transmissão e contágio da doença. Assim, a ênfase em procedimentos excessivamente higiênicos como a separação dos utensílios domésticos e o afastamento de qualquer coisa ou pessoa que 
a mulher possa contaminar pelo toque tornando-a intocável, são supostamente utilizados como prevenção do contágio.

Uma vez fui à casa de minha irmã, eu gosto muito de criança, e quando eu fui abraçar os netos dela, uma das netinhas disse para os outros: a mamãe falou que não é para a gente ficar muito agarrada com a titia, não é para a gente ficar abraçando muito ela. Aquilo me doeu muito, fui para casa arrasada. (u.c.e $n^{o} 337$ / u.c.i $n^{\circ} 15$ ).

O pior foi que a tia da minha filha levou a minha filha para morar com ela, para que ela não pegasse a doença. Eu estava totalmente só, a minha mãe não mora comigo e os meus irmãos é o mesmo que estar só, passam o dia na rua jogando bola. (u.c.e $n^{o}$ 415 / u.c.i $\left.n^{\circ} 20\right)$.

A explicação para a conduta explicitada na u.c.e $n^{0} 415$ deve-se ao desconhecimento do tratamento e de sua ação sobre os bacilos. Por esse motivo, recorre aos tempos em que os filhos eram tirados dos pais e levados aos preventórios como medida profilática, demonstrando que este conhecimento e prática frente ao contagio ainda perdura.

Por outro lado, as ações de controle da hanseníase enfatizam a vigilância dos contatos domiciliares, pela importância epidemiológica desse grupo na detecção precoce de casos. Para fins operacionais, são considerados contato intradomiciliar toda e qualquer pessoa que resida ou tenha residido nos últimos cinco anos com o doente, devendo o mesmo ser submetido a exame dermatoneurológico e receber orientações quanto ao período de incubação, transmissão, sinais e sintomas da hanseníase e do retorno ao serviço de saúde no caso de surgimento de qualquer alteração suspeita, além de duas doses da vacina BCG-id, com intervalo mínimo de seis meses entre a primeira e a segunda dose. ${ }^{16}$

Outra reflexão acerca do controle dos contatos deve-se a que sendo este grupo chamado para submissão às atividades de controle, ele é alertado para a doença pelas próprias ações de controle do programa, e estas acionam o imaginário. Decorrentes disso, as mulheres não podem lançar mão das estratégias de autoproteção, como: mentir sobre a causa das alterações em seus corpos, escondê-las por meio de roupas ou deixando de ir a lugares que antes frequentavam ou ocultar o diagnóstico e tratamento, pois as próprias ações de vigilância epidemiológica da doença se incumbem de torná-la pública pela chamada de seus contatos, os quais, muitas vezes, fazem o exame e recebem a vacina BCG. Porém, não recebem orientações sobre como agir e se cuidar e, com isso, são impedidos de acrescentar novos saberes aos já existentes, cerceando-os de difundirem conhecimentos atualizados sobre a doença e desconstruírem crendices, mitos e ações sobre o contágio da hanseníase, que reforçam preconceitos e sustentam estigmas.

O sofrimento das mulheres ao tornar público que têm ou tiveram hanseníase, e o modo como foram humilhadas e discriminadas pelos familiares, ou seja, por aqueles de quem elas esperavam 
apoio e compreensão, repercute em suas próprias representações da doença. O apoio da família é essencial para dar suporte às mulheres e, muitas vezes ajudá-las a superar o impacto do diagnóstico e o autopreconceito com relação à hanseníase, ajudando na adesão ao tratamento e na prática dos cuidados prescritos. ${ }^{17}$

Nesta classe, as mulheres optaram por contar aos amigos ou alguém se incumbiu de fazê-lo, tornando pública a sua doença e expondo-as ao preconceito e afastamento dos 'amigos'.

Meus amigos se afastaram de mim, minhas amigas também se afastaram [...]. (u.c.e $n^{o} 343$ / u.c.i $n^{o} 15$ ).

[...] Quando eu falo em excluir, falo daqueles que diziam que eram amigos e que foram se afastando aos poucos. (u.c.e $n^{\circ} 283$ / u.c.i $\left.n^{\circ} 24\right)$.

[...] Falei para poucos amigos, porque existem muitas pessoas que têm preconceito. Os que eu falei se afastaram [...]. (u.c.e $n^{o} 753 /$ u.c.i $\left.n^{o} 35\right)$.

Esses comportamentos discriminatórios estão provavelmente ancorados na fragmentação de conhecimentos sobre a doença, conhecimentos esses de domínio da equipe de saúde, que não são difundidos para o público em geral, ou, quando o são, não causam impacto suficiente ao ponto de estimular as mulheres a tornarem-se agentes difusores de conhecimentos sobre a hanseníase, contribuindo para a desconstrução de saberes sobre o contágio, já superados pelas descobertas da ciência, em seu meio social. Ao contrário, existe uma lacuna a esse respeito, parece que ainda vivem no tempo em que a Colônia de Marituba funcionava e confinava seus moradores. Essa lacuna é preenchida por um sistema de significações, expressos como comportamentos significantes, cuja função é reduzir a tensão psicológica diante do medo do contágio e de funcionar como defesa diante da iminência de adoecer pela hanseníase.

\section{CONSIDERAÇÕES FINAIS}

Os resultados apontam o preconceito das pessoas que têm maior proximidade com a portadora ou ex-portadora de hanseníase, e como se posicionam frente à possibilidade de contrair essa doença. Enquanto não houver respostas efetivas com vistas ao entendimento do contágio da hanseníase, as pessoas continuarão criando mecanismos cognitivos e afetivos para entender e proteger-se da mesma, afastando-se simbolicamente do seu contágio. Desta forma, observa-se que as práticas de autoproteção dos familiares das mulheres estudadas estão ancoradas nas representações sociais da lepra, ou seja, no preconceito, além de informações, embora fragmentadas, transmitidas através das chamadas para comparecerem à unidade para submissão ao exame de contatos.

A teoria das representações sociais permitiu o entendimento de como se dá a articulação entre os elementos na construção dos saberes sociais que vão repercutir nas práticas relacionadas ao problema e o contexto cultural onde ocorrem tais práticas. Essa construção simbólica ocorre em 
Marituba, onde se tem um ambiente propício de circulação de saberes, de imaginário, de simbologias, de imagens que congelaram e não conseguem desentranhar do ambiente e, por isso, tornaram-se 'marcas', mas precisamente, 'marcas do ambiente'.

Então, no contexto de Marituba circulam imagens, imaginários, simbologia, mitos, comportamentos, pessoas que vivenciaram a Colônia de Marituba, cujo resgate da memória social traz à luz da atualidade as questões do passado que retroalimentam as representações sociais, vivificando-as. Nesse encadeamento, a memória social da lepra em Marituba imprime e marca, porque as pessoas que viveram na Colônia ou que tiveram parentes próximos que lá viveram, a todo o momento evocam suas reminiscências trazendo-as à tona, retroalimentando e reforçando as imagens que sustentam as representações sociais circulantes.

Assim, por mais que se tenham as campanhas do Ministério da Saúde com a veiculação de um novo discurso, novas imagens e novos saberes, em Marituba se tem a memória social, as imagens dos mutilados, o Abrigo João Paulo II, no qual ainda vivem 148 asilados que não tinham para onde ir após a desativação da Colônia, e as casas que eram doadas aos hansenianos que casavam e passavam a constituir famílias.

Frente a essa interpretação, as mulheres com alterações corporais pela hanseníase sofrem preconceito e discriminação de outras pessoas, que, por medo do contágio e alimentadas pelo imaginário da lepra, passam a ter comportamentos significantes sociais para com elas, pois as marcas existentes em cada uma dessas mulheres transcendem as cicatrizes e sequelas da doença e subsistem, também, em suas subjetividades ao longo dos tempos, decorrente da desinformação a respeito da doença.

O enfermeiro, ao planejar, desenvolver ações educativas e intervir junto às ações de controle da hanseníase, deverá estar atento às necessidades do grupo, de forma que os conteúdos abordados atendam às diferentes pertenças (sejam estes portadores, ex-portadores e contatos de hanseníase). Porém, isso só é possível a partir de uma abordagem integral, pois, no que tange às mulheres com o corpo alterado pela hanseníase, há necessidade de se entender todo o processo de subjetividade pelos quais elas passam no que se refere ao resgate da autoestima, de modo que as ações relativas ao cuidado de si sejam ensinadas reflexivamente, incentivando o autocuidado e a aquisição de uma autoimagem positiva.

A captação dos dados expôs a realidade de um grupo específico de pessoas da região norte com baixo nível socioeconômico e baixa escolaridade, moradores de contextos arraigados de representações sociais preconceituosas sobre a hanseníase, cujos resultados atrelam-se à memória social de um local/sede de uma antiga colônia de hansenianos.

Em virtude disso, traz à tona uma realidade social muitas vezes mascarada por impressões geradas pelo fato de que os muros da colônia não existem mais. Observa-se, no entanto, que a 
despeito de sua derrubada, os espaços e limites do convívio social das mulheres, sujeitos deste estudo, são delimitados, persistem e resistem aos anos e ao tempo em que duram as ideias de um passado sobre a lepra que subsiste à hanseníase.

A despeito da relevância deste estudo para a enfermagem como prática social, outros estudos permitirão gerar outros resultados na dependência das realidades pesquisadas. Assim, recomendamse estudos comparativos com o mesmo objeto, porém voltados para realidades distintas.

\section{REFERÊNCIAS BIBLIOGRÁFICAS}

1. Mattos DM, Fornazari SK. A lepra no Brasil: representações e práticas de poder. Cadernos de Ética e Filosofia Política. 2005; 6 (1): 45-57.

2. Minuzzo DA. O homem paciente de hanseníase (lepra): representação social, rede social familiar, experiência e imagem corporal. [dissertação mestrado]. Évora (PT): Universidade de Évora; 2008.

3. MORHAN. Dossiê: a história dos filhos órfãos de pais vivos no Brasil. [on-line]. [citado 11 mar 2011]; Disponível em: http://www.morhan.org.br

4. Jovchelovitch S. Os Contextos do Saber: representações, comunidade e cultura. Tradução de Pedrinho A. Guareschi. Petrópolis (RJ): Vozes; 2008.

5. Moscovici S. A representação social da psicanálise. Rio de Janeiro (RJ): Zahar; 1978.

6. Oliveira MHP de, Gomes R, Oliveira CM de. Hanseníase e sexualidade: convivendo com a diferença. Rev. Latino-Am. Enfermagem, [on-line]. 1999 Jan; [citado 13 mar 2011]; 7(1): 85-91. Disponível em: http://www.scielo.br/scieloOrg/php/reference.php?pid=S01041169199900010001 $\underline{1 \& \text { caller }=\text { www.scielo.br\&lang }=\text { en }}$

7. Ferreira MA. O corpo no cuidado de enfermagem: representações de clientes hospitalizados. [tese de doutorado]. Rio de Janeiro (RJ): Escola de Enfermagem Anna Nery/UFRJ; 1999.

8. Marques SC, Tyrrel MAR, Oliveira DC de. Imagens e significados da Aids entre usuárias dos serviços da rede básica de saúde dos municípios do Rio de Janeiro. Psicol. teor. prat. 2009; 11 (3): 97-113.

9. Nascimento-Schulze CM, Camargo BV. Psicologia social, representações sociais e métodos. Temas de Psicologia 2000; 8 (3): 287-299.

10. Gomes AMT, Oliveira DC de, Marques SC. A representação social do trabalho do enfermeiro na programação em saúde. Psicol. teor. prat, [online]. 2004; [citado 17 mar 2011]; 6 (n.esp.): 7990. Disponível em: http://pepsic.bvsalud.org/scielo.php?script=sci isoref\&pid=S1516368720040 $\underline{00300006 \& \text { Ing }=p t \& t \operatorname{lng}=p t}$

11. Femina LL, Soler ACP, Nardi SMT, Paschoal VDA. Lepra para hanseníase: a visão do portador sobre a mudança de terminologia. Hansen Int, [ on-line]. 2007; [citado 12 mar 2011]; 32(1): 37-48. Disponível em:http://www.ilsl.br/revista/index.php/hi/article/viewFile/302/279 
12. Lei ${ }^{\circ} 9.010$ de 29 de março de 1995. Dispõe sobre a terminologia oficial relativa à hanseníase e dá outras providências. Diário Oficial da União, Brasília (DF), de 30 mar 1995.

13. Ministério da Saúde (BR). Guia de vigilância epidemiológica. Secretaria de Vigilância em Saúde. Departamento de Vigilância Epidemiológica. Brasília (DF): 2010. 816 p.

14. Jodelet D. Representações do contágio e a Aids. In: Jodelet D, Madeira M. (organizadoras). Aids e representações sociais: a busca de sentidos. Natal (RN): EDUFRN; 1998. p. 17-45.

15. Balaiardi KS. O estigma da hanseníase: relato de uma experiência em grupo com pessoas portadoras. Hanseno. Int. (on-line). 2007; [citado 11 mar 2011]; 32 (1): 27-36. Disponível em: http://www.ilsl.br/revista/index.php/hi/article/viewFile/301/278

16. Ministério da Saúde (BR). Guia para o Controle da hanseníase. Secretaria de Políticas de Saúde. Departamento de Atenção Básica. Brasília (DF): 2002. 89 p.

17. Sangi KCC, Miranda LF de, Spindola T, Leão AMM. Hanseníase e estado reacional: história de vida de pessoas acometidas. Rev. enferm. UERJ, Rio de Janeiro, 2009 abr/jun; 17(2): 209-14.

Artigo apresentado em 25/01/14

Artigo aprovado em 18/08/14

Artigo publicado no sistema em 12/09/14 